\title{
Low-molecular-weight fucoidan enhances the proangiogenic phenotype of endothelial progenitor cells
}

\author{
Faouzia Zemani ${ }^{a}$, Danielle Benisvy ${ }^{a}$, Isabelle Galy-Fauroux ${ }^{a}$, Anna Lokajczyk ${ }^{a}$, Sylvia Colliec-Jouault ${ }^{b}$, \\ Georges Uzanc, Anne Marie Fischer ${ }^{\mathrm{a}}$ and Catherine Boisson-Vidal ${ }^{\mathrm{a}, \text { * }}$ \\ a INSERM U428, 4 av. de l'Observatoire, Faculté de Pharmacie, 75270 Paris Cedex 06, France \\ b IFREMER, Route de l'lle d'Yeu, Nantes, France \\ ${ }^{c}$ INSERM U506, Hôpital Paul Brousse, Villejuif, France \\ *: Corresponding author : Tel.: +33 1537398 28; fax: +33 1440717 72; catherine.boisson-vidal@univ-paris5.fr
}

\begin{abstract}
:
Endothelial progenitor cell (EPC) transplantation is a potential means of inducing neovascularization in vivo. However, the number of circulating EPC is relatively small, it may thus be necessary to enhance their proangiogenic properties ex vivo prior to injection in vivo. Fucoidan has previously been shown to potentiate in vitro tube formation by mature endothelial cells in the presence of basic fibroblast growth factor (FGF-2). We therefore examined whether fucoidan, alone or combined with FGF-2, could increase EPC proangiogenic potency in vitro. EPC exposure to $10 \mu \mathrm{g} / \mathrm{ml}$ fucoidan induced a proangiogenic phenotype, including cell proliferation $(p<0.01)$ and migration $(p<0.01)$; moreover, differentiation into vascular cords occurred in the presence of FGF-2 $(p<0.01)$. This latter effect correlated with upregulation of the cell-surface $\alpha 6$ integrin subunit of the laminin receptor $(p<0.05)$. Compared to untreated HUVEC, untreated EPC a6 expression and adhesion to laminin were enhanced two-fold. Fucoidan treatment further enhanced HUVEC but not EPC adhesion to laminin. These results show that fucoidan enhances the proangiogenic properties of EPC and suggest that ex vivo fucoidan preconditioning of EPC might lead to increased neovascularization when injected into ischemic tissues.
\end{abstract}

Keywords: Alpha 6; Angiogenesis; Endothelial progenitor cells; FGF-2; Fucoidan

\begin{abstract}
Abbreviations: EPC, endothelial progenitor cells; ECM, extracellular matrix; FGF-2, basic fibroblast growth factor; FACS, fluorescence-activated cell sorting; FCS, fetal calf serum; HUVEC, human umbilical vein endothelial cell; PBS, phosphate buffered saline; VEGF, vascular endothelial growth factor; KDR, vascular endothelial growth factor receptor-2; vWF, von Willebrand factor
\end{abstract}




\section{INTRODUCTION}

Angiogenesis is a multistep process whereby new blood vessels develop from the pre-existing vasculature. It involves migration, proliferation and differentiation of mature endothelial cells, and is regulated by interactions of endothelial cells with angiogenesis-inducing factors (growth factors, cytokines, etc.) and extracellular matrix components [1]. Endothelial cells participate in the revascularization of ischemic tissues downstream of a thrombus. Endothelial progenitor cells (EPC), which originate from bone marrow, also migrate to sites of ischemia and are incorporated into neovessels [2]. EPC hold great promise as autologous cell therapy products for patients with vascular diseases associated with heart or leg ischemia [3-5], potentially offering a safer alternative to local injection of pro-angiogenic growth factors like VEGF. Transplantation of bone marrow mononuclear cells has already been shown to improve tissue function in heart and leg ischemia [4;6-8]. However, in a murine system, only 5 to $20 \%$ of transplanted $\mathrm{CD}_{3} 4^{+}$cells were recoverable in the bone marrow, with maximal seeding occurring 1 to $3 \mathrm{~h}$ after infusion [9]. Furthermore, only 5\% to $30 \%$ of neocapillaries originated from engrafted cells [10-13]. Such a low yield implies that large blood volumes would be necessary for clinical applications. One potential way of overcoming this limitation is to enhance the angiogenic properties of EPC ex vivo.

Fucoidans are high-molecular-weight sulfated polysaccharides extracted from brown seaweeds. Reduced into low-molecular-weight fractions, fucoidans have been used for in vivo studies. They exhibit the same antithrombotic activity as heparin in rabbits, but have lower anticoagulant activity and carry a lower hemorrhagic risk [14]. Besides their anticoagulant and antithrombotic activities, fucoidans can induce angiogenesis in vitro by modulating the proangiogenic properties of heparin-binding growth factors such as basic fibroblast growth factor (FGF-2). This pro-angiogenic effect is related to their molecular weight and sulfate content $[15 ; 16]$. Owing to their ionic structure, fucoidans can bind a large number of proteins [17-19]. They can thereby interfere with cell-cell and cell-matrix adhesion, and promote the release of growth factors bound to the cell surface.

We have previously demonstrated that a low-molecular-weight fucoidan fraction extracted from the brown algae Ascophyllum nodosum enhances FGF-2-induced vascular tube formation by mature endothelial cells in a standard in vitro Matrigel model [20;21]. Tube formation was dependent on overexpression of the $\alpha 6$ subunit of the $\alpha 6 \beta 1$ laminin receptor on the endothelial cell surface [20]. Unexpectedly, and contrary to results obtained with unfractionated heparin, $\alpha 6$ over-expression required the presence of heparan sulfate proteoglycans (FGF-2 low-affinity receptors), but not FGF-2 high-affinity receptors at the cell surface [21].

Here we studied the effect of this fucoidan fraction on the three main steps of angiogenesis, in order to determine whether it enhances the pro-angiogenic capacity of EPC in vitro.

\section{MATERIALS AND METHODS}

\subsection{Materials.}

Low-molecular-weight (LMW) fucoidan was obtained by radical depolymerization of highmolecular-weight fucoidan extracted from Ascophyllum nodosum, using procedures adapted from Nardella et al. [22]. The molecular weight was determined to be $4 \pm 1 \mathrm{kDa}$ by highperformance steric chromatography (HPSEC) in $0.15 \mathrm{M} \mathrm{NaCl}, 0.005 \mathrm{M} \mathrm{NaH}_{2} \mathrm{PO}_{4}$ at $\mathrm{pH} 7.0$, using pullulans (Polymers Laboratories, Interchim, Paris, France) and LMW heparin fractions as standards. The chemical composition was as follows: $34 \%$ fucose, $4 \%$ galactose, $3 \%$ xylose, $3 \%$ uronic acid and 4\% sulfate. FGF-2 was from Valbiotech (Paris France). Laminin 
and growth factor-reduced (GFR) Matrigel were from Becton-Dickinson (Le Pont de Claix, France). An R-phycoerythrin (R-PE)-conjugated mouse anti-human monoclonal antibody against CD34 and an R-PE-conjugated rat anti-human monoclonal antibody against CD31 were purchased from Immunotech (Immunotech, Marseille, France). An R-PE-conjugated rat anti-human monoclonal antibody against $\alpha_{6}$ integrin subunits, R-PE-conjugated mouse antihuman IgG, and 7-amino-actinomycin D (7-AAD - VIA-probe ${ }^{\mathrm{TM}}$ ) were purchased from Pharmingen International (Le Pont de Claix, France). Mouse anti-human monoclonal antibodies against KDR were from Sigma (Saint Quentin Fallavier, France), Flt-1 and Tie-2 from Becton Dickinson (Le Pont-de-Claix, France) and VE-Cadherin (CD144) from Santa Cruz Biotechnology (Tebu-bio, France). RPE-conjugated goat anti-mouse F(ab') ${ }_{2}$ and FITCconjugated phalloidin were from Beckman Coulter (Villepinte, France).

\subsection{Cell isolation and EPC culture}

Umbilical cord blood was diluted in an equal volume of HBSS, and mononuclear cells were isolated by density-gradient centrifugation using $1.077 \mathrm{~g} / \mathrm{ml}$ Histopaque solution (Sigma Chemicals, Saint Quentin Fallavier, France) as described by Bompais et al [23]. CD34 ${ }^{+}$cells (90\% purity) were selected with immunomagnetic beads and the MACS technique (Miltenyi Biotec, Paris, France). They were plated in 24-well gelatine-coated plastic culture dishes in endothelial basal medium (EBM-2; BioWhittaker, Cambrex, France) supplemented with SingleQuots endothelial growth medium and 5\% FCS. After 4 days in culture, non-adherent cells were removed by thorough washing with culture medium. When an EPC colony became visible microscopically, the cells were detached with trypsin-EDTA (Eurobio, Les Ulis, France) and expanded for further analysis.

Endothelial cells from human umbilical cords (HUVEC) were isolated by enzymatic digestion as previously described [20].

\subsection{FACS Analysis}

Expression of cell-surface antigens on fucoidan-treated and untreated EPC was analysed by immunofluorescence with a FACS-SORT flow cytometer (BD Biosciences). Labelling with mouse anti-human KDR, Flt-1, Tie-2 and VE-cadherin was visualised by using RPEconjugated goat anti-mouse $\mathrm{F}\left(\mathrm{ab}{ }^{\prime}\right)_{2}$. CD34, CD31 and $\alpha 6$ were used directly PE-conjugated. In each immunofluorescence experiment an isotype-matched IgG antibody was used as a control and the fluorescence intensity of stained cells was gated according to established methods. Data were analysed with CellQuest ${ }^{\mathrm{TM}}$ software (Becton Dickinson).

\subsection{Outgrowth cell proliferation assay}

EPC were seeded at a density of $5 \times 10^{4}$ per well in 24-well gelatine-coated plates and incubated overnight with EGM-2. The use of similar initial seeding densities was confirmed 16 hours after plating by measuring acid phosphatase activity as previously described [24]. All cells were then growth-arrested for 24 hours in serum-free EBM-2 2\% FCS. Cells were released from growth arrest by adding basal medium, 5\% FCS (referred to as basal medium), with or without various fucoidan concentrations. The cell number in each well was determined by cell titre assay 49 hours after serum stimulation, and viability was evaluated by trypan blue exclusion. Absorbance was expressed as a ratio of values obtained immediately after seeding. 


\subsection{Adhesion assay}

Adhesion assays were performed as previously described [25] in 96-well polystyrene plates (Costar, France) precoated with murine laminin (5 $\mu \mathrm{g} /$ well) (Becton-Dickinson, France). After incubation, non-adherent cells were washed off and the number of adherent cells was determined by alkaline phosphatase assay (pNPP). Each data point was the average of 3 wells, and each experiment was performed at least 3 times. Percentage adhesion was calculated from the number of adherent cells and the total number of cells plated per well. For inhibition experiments, antibody $\alpha 6$ was used at 10 to $20 \mu \mathrm{g} / \mathrm{ml}$, a concentration that inhibited EPC adhesion to laminin in preliminary experiments.

\subsection{In vitro tube formation assay}

EPC were seeded in 6-well gelatine-precoated plates at a density of $1.510^{5} /$ well. After $18 \mathrm{~h}$ the culture medium was replaced by medium containing the sulfated polysaccharide $(10 \mu \mathrm{g} / \mathrm{ml})$ supplemented with 5\% FBS, with or without FGF-2 (5 ng/ml). After $36 \mathrm{~h}$, EPC were detached with versene $/ 0.01 \%$ collagenase $(1 / 1)$, centrifuged at $200 \mathrm{~g}$ for $7 \mathrm{~min}$ at $4^{\circ} \mathrm{C}$, washed twice with buffered Hank's, 0.5\% BSA, and used for FACS analysis and tube formation assay as previously described [20]. Briefly, growth-factor-reduced Matrigel (150 $\mu$ l, $7 \mathrm{mg} / \mathrm{ml}$, Becton Dickinson) was added to each well of refrigerated 48-well plates and allowed to solidify for at least $1 \mathrm{~h}$ at $37^{\circ} \mathrm{C}$. Untreated EPC and EPC treated for $36 \mathrm{~h}$ with or without FGF-2 in the presence or absence of $10 \mu \mathrm{g} / \mathrm{ml}$ fucoidan were cultured for $18 \mathrm{~h}$ in unsupplemented medium (EBM2) with $5 \% \mathrm{FCS}$ at $37^{\circ} \mathrm{C}$ in humidified air supplemented with $5 \% \mathrm{CO}_{2}$. The cells were then fixed with $1.1 \%$ glutaraldehyde for $15 \mathrm{~min}$ and stained with Giemsa for $3 \mathrm{~min}$. Tube formation was examined by phase-contrast microscopy. The total enclosed area delimited by the tubes and the total length of tube structures were quantified on the entire surface of each well by using Videomet software (Microvision Instruments, France).

\subsection{Chemotaxis Assay}

Chemotaxis was examined in 48-well modified Boyden chambers (Costar, Avon, France). Eight-micrometer pore-size polyvinylpyrrolidone-free polycarbonate Nucleopore filters (Costar, Avon, France) were coated with gelatine by immersing them overnight in a solution of $200 \mathrm{mg} / \mathrm{ml}$ gelatine in $0.1 \%$ acetic acid, and were then dried. The chamber was inserted in a 24-well culture dish containing EBM2, 5\% FCS with $40 \mathrm{ng} / \mathrm{ml}$ human recombinant VEGF (positive control) or $100 \mathrm{ng} / \mathrm{ml} \mathrm{MCP-1}$ (negative control). Control and fucoidan-treated EPC were washed in PBS and detached with $1 \mathrm{mM}$ EDTA in PBS (pH 7.4); 3 to $5 \times 10^{5}$ cells $/ \mathrm{ml}$ in EBM2 supplemented with $0.1 \%$ BSA, $5 \%$ FCS were placed in the upper chamber. Migration was allowed to proceed for 6 hours at $37^{\circ} \mathrm{C}$ in air-5\% $\mathrm{CO}_{2}$. Cells remaining on the upper surface of the filters were mechanically removed, and the filters were then fixed with $1.1 \%$ formaldehyde and stained with Giemsa. The number of cells that had migrated to the lower surface was determined by counting under a high-power microscope (x40 objective). All conditions used in a given experiment were tested in triplicate. A migration index was calculated as the ratio of the number of cells that migrated toward the conditioned medium to the number of cells that migrated towards serum-free culture medium.

\subsection{Actin polymerisation assay}

EPC seeded on multiwell slides were fixed with $4 \%$ paraformaldehyde at RT for 10 min, then washed with PBS, permeabilized with $0.2 \%$ triton and stained with FITC-conjugated phalloidin (2 mg/ml, Sigma). The cells were coverslipped with glycerol/PBS (9:1) containing 
Hoechst 33258 (2.5 $\mu \mathrm{g} / \mathrm{mL}$, Sigma) to identify cell nuclei and were evaluated by fluorescence microscopy.

\subsection{Statistical Analysis}

Data are expressed as means \pm SEM of at least three independent experiments. Statistical analysis was based on a two-tailed $t$ test or on ANOVA for multiple comparisons.

\section{RESULTS}

\subsection{EPC exhibit higher angiogenic capacity than HUVEC}

Undifferentiated progenitor cells were isolated from human umbilical cord bloods on the basis of CD34 expression. Their outgrowth was examined between 20 and 60 days and was compared to that of mature endothelial cells extracted from human umbilical veins (HUVEC). When cultured in EGM-2 medium containing specific endothelial growth factors, these human $\mathrm{CD}^{+}{ }^{+}$cells formed small colonies and, after 11 days, exhibited the typical "cobblestone" morphology of endothelial cells (Fig. 1A). The expansion of these endothelial progenitor cells (EPC) reached $10^{4}$-fold $(n=4)$ after 15 days, with a doubling time 6 times shorter than that of HUVEC in the same experimental conditions (Fig. 1B). Relative to HUVEC, EPC had a higher capacity to form capillary-like structures in the in vitro tube formation assay. In the same experimental conditions, EPC adhered very quickly, branched and formed capillary-like structures that formed enclosed areas within $18 \mathrm{~h}$, whereas HUVEC only differentiated into a partially organised capillary network (Fig. 1C).

As already reported, and despite the differences in outgrowth, HUVEC and EPC differed by their expression of the hematopoietic stem cell marker CD133. As shown in Table 1, CD133 expression was rapidly down-regulated as EPC differentiated and, after 60 days, reached a level similar to that of HUVEC. All the following experiments were thus performed during the first 30 days of culture. EPC expressed endothelial-specific markers such as Tie-2, KDR, Flt-1, CD144 and CD31. The expression of some of these markers varied during maturation and reached levels similar to those of HUVEC (Table I). EPC were uniformly positive for vWF, and transmission electron microscopy showed the presence of Weibel-Palade bodies [23]. The combined expression of these markers unequivocally confirmed the endothelial nature of the EPC thus obtained.

Table 1 : Means fluorescence intensity of EPCs and HUVECs phenotypic markers analysed by flow cytometry (mean $\pm \mathrm{SD}, \mathrm{n}=5$ )

\begin{tabular}{c|cc|c}
\hline & \multicolumn{2}{|c|}{ EPCs } & HUVECs \\
& D 30 & D 60 & \\
\hline CD133 & $15.0 \pm 2.0$ & $1.5 \pm 0.1$ & $1.8 \pm 0.1$ \\
Tie-2 & $6.1 \pm 0.5$ & $12.9 \pm 0.1$ & $2.6 \pm 0.1$ \\
KDR & $8.8 \pm 0.4$ & $1.8 \pm 0.1$ & $3.4 \pm 0.1$ \\
CD144 & $21.8 \pm 0.3$ & $10.6 \pm 0.4$ & $13.2 \pm 0.1$ \\
FIt-1 & $1.0 \pm 0.1$ & $1.0 \pm 0.2$ & $0.9 \pm 0.1$ \\
CD31 & $36.3 \pm 0.2$ & $26.3 \pm 0.1$ & $27.1 \pm 0.1$ \\
\hline
\end{tabular}




\subsection{Fucoidan enhances EPC proliferation}

We first examined the effect of various fucoidan concentrations on EPC proliferation. EPC were incubated in basal medium with fucoidan concentrations ranging from 0.1 to $100 \mu \mathrm{g} / \mathrm{ml}$ and were counted $49 \mathrm{~h}$ later. Fucoidan enhanced EPC proliferation in a concentrationdependent manner, starting at $1 \mu \mathrm{g} / \mathrm{ml}$, whereas it had no effect on HUVEC at concentrations below $100 \mu \mathrm{g} / \mathrm{ml}$ (Fig. 2). Whatever the fucoidan concentration, EPC always proliferated significantly more strongly than HUVEC.

\subsection{Fucoidan enhances FGF-2-induced vascular tube formation by EPC}

EPC were incubated overnight in starvation medium then stimulated for $36 \mathrm{~h}$ with fucoidan in basal medium, with or without FGF-2, before seeding on Matrigel for $18 \mathrm{~h}$. Without FGF-2 pretreatment (Fig. 3A), EPC formed no tubular structures, even in the presence of $10 \mu \mathrm{g} / \mathrm{ml}$ fucoidan (Fig. 3B), remaining as individual cells or small aggregates. In contrast, $18 \mathrm{~h}$ after seeding, FGF-2-pretreated cells were elongated and interconnected (Fig. 3C); the tubular network was significantly more extensive in the presence of $10 \mu \mathrm{g} / \mathrm{ml}$ fucoidan, inferring enhanced differentiation (1.8-fold, $\mathrm{p}<0.001)$ (Fig. 3D). These latter results were similar to those obtained with HUVEC in the same conditions $(\mathrm{p}=0.112)$ (Fig. 3E). The effect was fucoidan concentration-dependent and was also related to the fucoidan sulfate content, as desulfated fucoidan was less effective than the native molecule $((\mathrm{p}<0.01$; data not shown).

Figure 1: EPC had a higher angiogenic capacity than HUVEC. Panel A: morphology of progenitor endothelial cells (Phase-contrast micrograph, original x40). Panel B: Endothelial cell expansion from buffy-coat mononuclear cells from human cord blood compared to HUVEC $\bigcirc$. Results are cell numbers (mean $\pm \mathrm{SD}, \mathrm{n}=5$ up to passage $6, \mathrm{n}=3$ for subsequent passages). Panel C: Comparison of the capacity of endothelial cells to differentiate. After $36 \mathrm{~h}$ of pre-treatment with FGF-2 (5 ng/ml), EPC $(\square)$ and HUVEC (ם) were seeded in 48-well plates coated with Matrigel in growth factor-depleted basal medium. After $18 \mathrm{~h}$ of culture the cells were fixed with glutaraldehyde and stained with Giemsa. (Phase-contrast micrograph, original x10). Results are the means \pm SEM of 3 determinations. ** significantly $(\mathrm{p}<0.01)$ different from control.
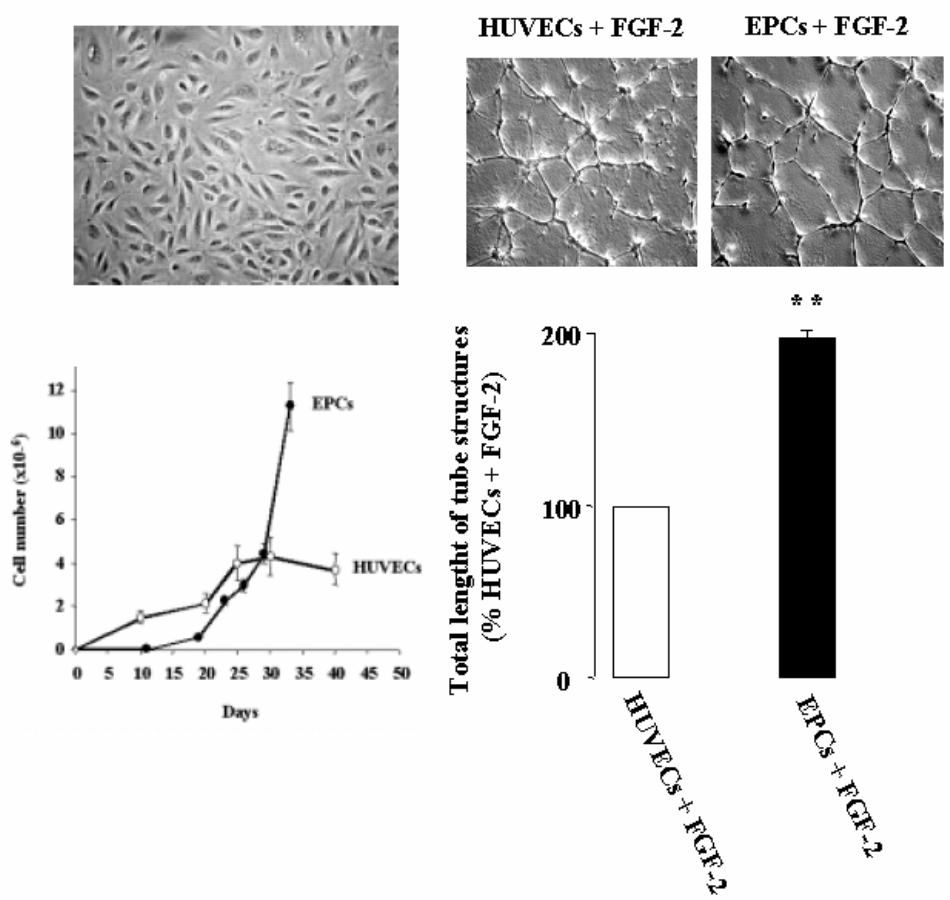

* *

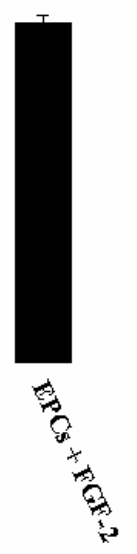


Figure 2: Influence of fucoidan $(0-100 \mu \mathrm{g} / \mathrm{ml})$ on EPC proliferation ( $\mathbf{\square})$ compared to HUVEC ( $\square$ ). The cells were stimulated with fucoidan in basal medium for 49 hours. Cell numbers were determined by pNPP colorimetric assay. Results are normalized to untreated HUVEC (basal medium). The experiments were repeated four times. *: $\mathrm{p} \leq 0.05-* *$ : $\mathrm{p} \leq 0.01-* * *$ : $\mathrm{p} \leq 0.001$

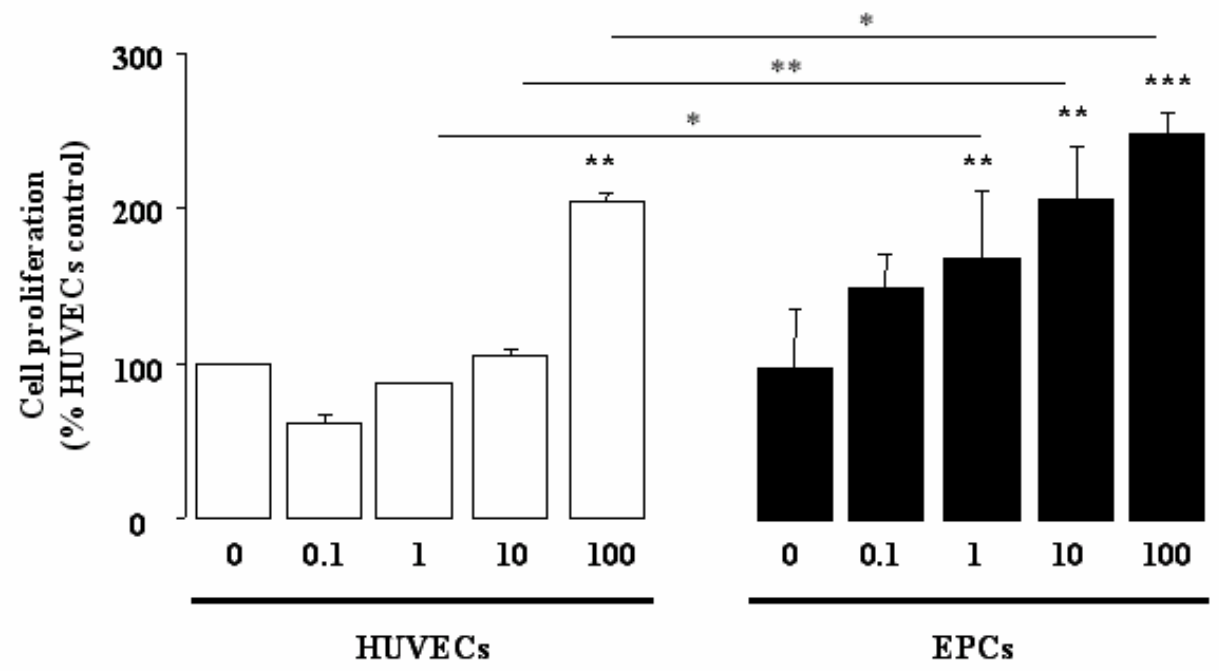

Fucoidan concentration $(\mu \mathrm{g} / \mathrm{ml})$

Figure 3: Fucoidan enhances FGF-2-induced tubular morphogenesis by EPC in Matrigel. After $36 \mathrm{~h}$ of culture in basal medium, with or without FGF-2 (5 ng/ml), in the presence or absence of $10 \mu \mathrm{g} / \mathrm{ml}$ fucoidan, as indicated, EPC (ם) and HUVEC $(\square)$ were immediately seeded on Matrigel in growth factordepleted basal medium. After $18 \mathrm{~h}$ of culture the cells were fixed with glutaraldehyde and stained with Giemsa (Phase-contrast micrograph, original x20). Panel A-D: Light micrographs showing the typical appearance of tubules formed by control and pretreated EPC in Matrigel. Panel E: comparison of the mean ( \pm SEM) total length of tubules (\% HUVEC control) formed in each in vitro assay. Results are the mean $\pm \mathrm{SE}$ of 3 determinations ${ }^{* * *} \mathrm{p} \leq 0.001,{ }^{* *} \mathrm{p}<0.01,{ }^{*} \mathrm{p}<0.05 \mathrm{n}=5$.

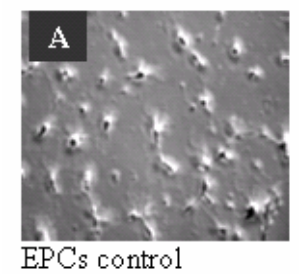

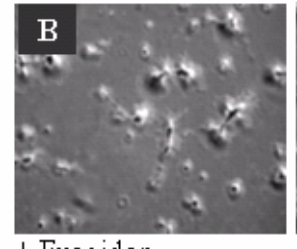

+ Fucoidan

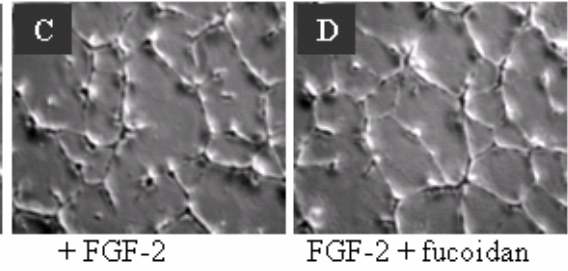

FGF-2 + fucoidan

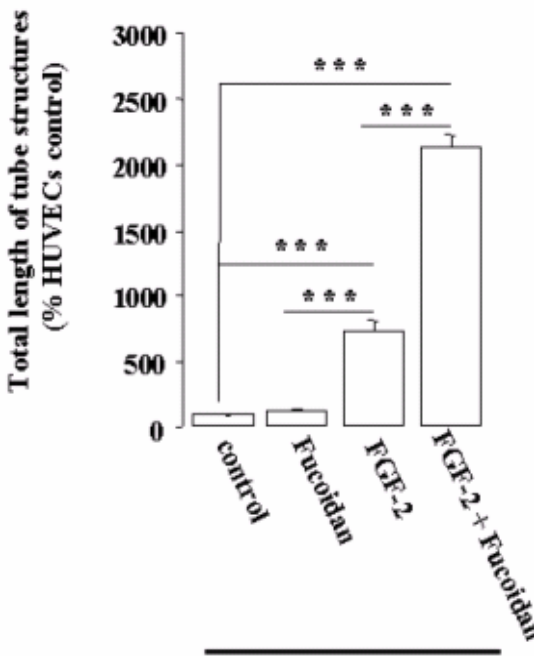

HUVECs

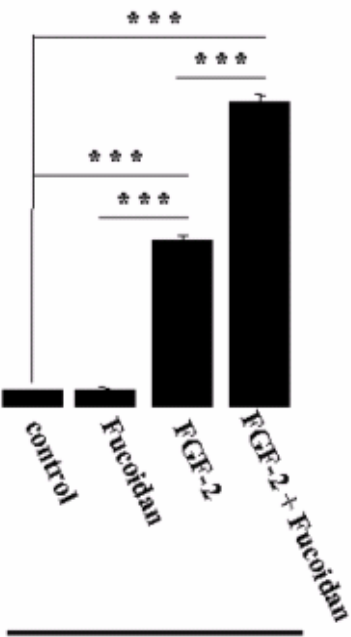

EPCs 


\subsection{Fucoidan enhances FGF-2-mediated $\alpha 6$ integrin over-expression by EPC}

Having previously shown that increased vascular tube formation by FGF-2-treated HUVEC correlates with over-expression of the $\alpha 6$ integrin subunit, we suspected that $\alpha 6$ subunit modulation might play a role in the observed effects of FGF-2 on EPC. Tubule formation by EPC on Matrigel was totally blocked by an anti- $\alpha 6$ antibody but was unaffected by an irrelevant isotype-matched antibody (Fig. 4A). The $\alpha 6$ integrin was more abundantly expressed on EPC than on HUVEC (190 000 vs 99000 sites per cell, respectively; $\mathrm{p}<0.001)$. FGF-2 treatment led to a 1.4-fold increase $(\mathrm{p}<0.01)$ in $\alpha 6$ labelling on the EPC surface (Fig. $4 \mathrm{~B}$ ), and to a 4.0-fold increase on the HUVEC surface ( $\mathrm{p}<0.001)$. Fucoidan treatment of FGF2-pretreated EPC did not lead to a significant further increase in $\alpha 6$ expression, whereas the same treatment of HUVEC resulted in a further 2-fold increase $(p<0.001)$. At the same concentration $(10 \mu \mathrm{g} / \mathrm{ml})$, fucoidan had no effect on the expression of other endothelial markers (KDR, Flt-1, Tie-2, PECAM, CD144) (data not shown). The kinetics of the increase in $\alpha 6$ integrin subunit expression was examined by harvesting EPC at various times after the addition of fucoidan and FGF-2. As shown in figure 4C, the increase in expression was detected at 16 hours and continued for 72 hours. Together, these observations suggested that $\alpha 6$ was involved in the formation of tubular structures by fucoidan and/or FGF-2-treated EPC.

Figure 4: Fucoidan enhances FGF-2-mediated over-expression of $\alpha 6$ integrin on EPC.

Panel A: Tubular morphogenesis induced by FGF-2 and/or fucoidan on Matrigel in the presence or absence of anti- $\alpha 6$ antibody (Phase-contrast micrograph, original x20). Panel B: FACS analysis of the effect of fucoidan on FGF-2-induced surface $\alpha 6$ subunit expression on EPC (ם) compared to HUVEC ( $\square$ ). Data are expressed as a percentage of the mean fluorescence intensity (mean \pm SE of 5 determinations) of untreated HUVEC. Panel C: kinetics of the fucoidan effect on FGF-2-induced $\alpha 6$ subunit expression. The cells were incubated without fucoidan and FGF-2 (control •), with 10 $\mu \mathrm{g} / \mathrm{ml}$ fucoidan (*), with $5 \mathrm{ng} / \mathrm{ml} \mathrm{FGF-2} \mathrm{( \square )} \mathrm{or} \mathrm{with} 10 \mu \mathrm{g} / \mathrm{ml}$ fucoidan and $5 \mathrm{ng} / \mathrm{ml} \mathrm{FGF}-2$ (ם), and analyzed by flow cytometry for surface labelling of the $\alpha 6$ subunit. Data are expressed as a percentage of the mean fluorescence intensity vs control (mean $\pm \mathrm{SE}$ of 5 determinations). ** $\mathrm{p}<0.01 ; * * * \mathrm{p}<0.001$ significantly different from control.

A
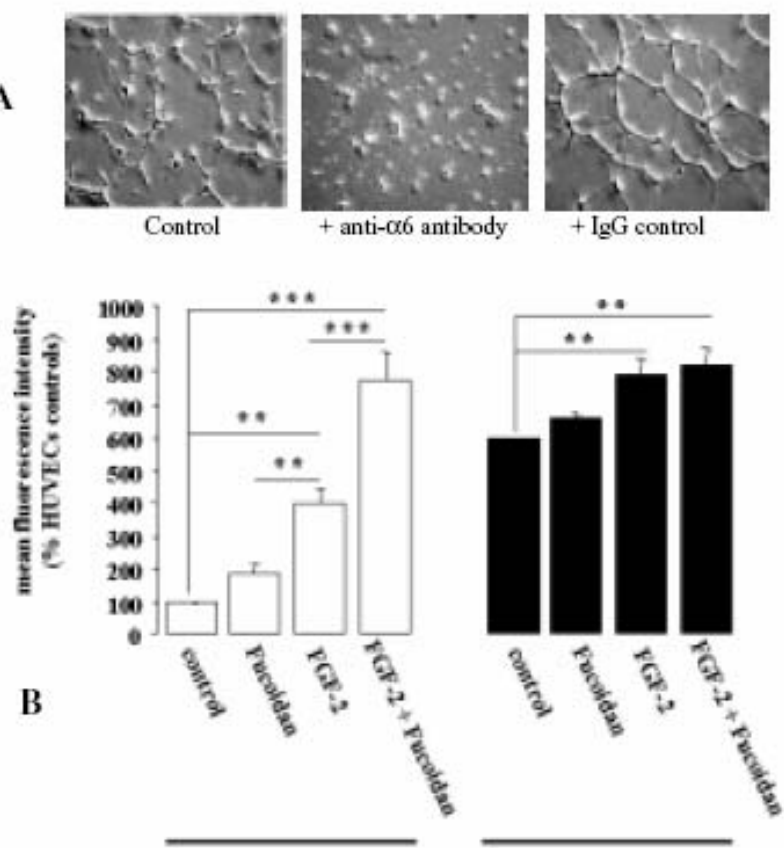

HUVEC,

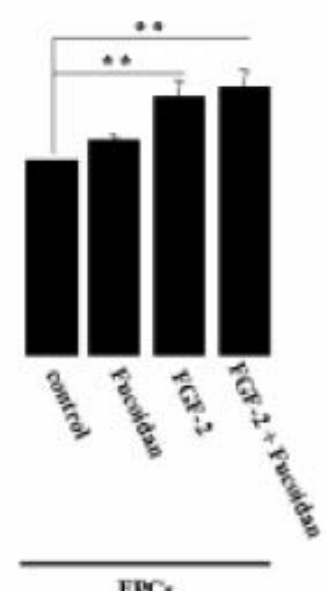

EPC;

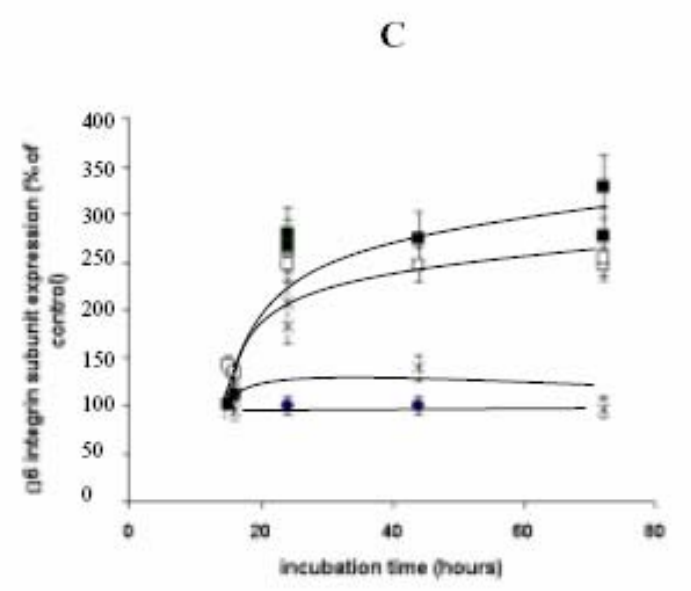




\subsection{Fucoidan pretreatment enhances HUVEC but not EPC attachment to laminin}

The combination of $\alpha 6$ and $\beta 1$ mediates cell adhesion to laminin, one of the main constituents of the basement membrane (and of Matrigel). We thus used a laminin adhesion assay to examine the functional significance of the observed increase in $\alpha 6$ subunit expression. Relative to HUVEC, untreated EPC showed 3-fold greater adhesion to laminin $(p<0.001)$ (Fig. 5). This adhesion was significantly inhibited by an anti- $\alpha 6$ antibody $(\mathrm{p}<0.001)$, but not by an isotype-matched mouse IgG. These results were consistent with the higher $\alpha 6$ integrin subunit expression by EPC compared to HUVEC. Fucoidan pretreatment significantly increased HUVEC adhesion to laminin (4-fold, $\mathrm{p}<0.001$ ), but had no detectable effect on EPC adhesion. This suggested that baseline $\alpha 6$ subunit expression on untreated EPC was probably already sufficient for maximal adhesion to laminin.

Figure 5: Fucoidan pretreatment enhances HUVEC but not EPC attachment to laminin. Untreated cells and fucoidan-treated cells were allowed to adhere to laminin for 20 minutes in the absence or presence of anti $\alpha 6$ antibody as indicated. The proportion of adherent cells was determined by pNPP colorimetric assay. Results are the means $\pm \mathrm{SD}$ of 3 experiments.

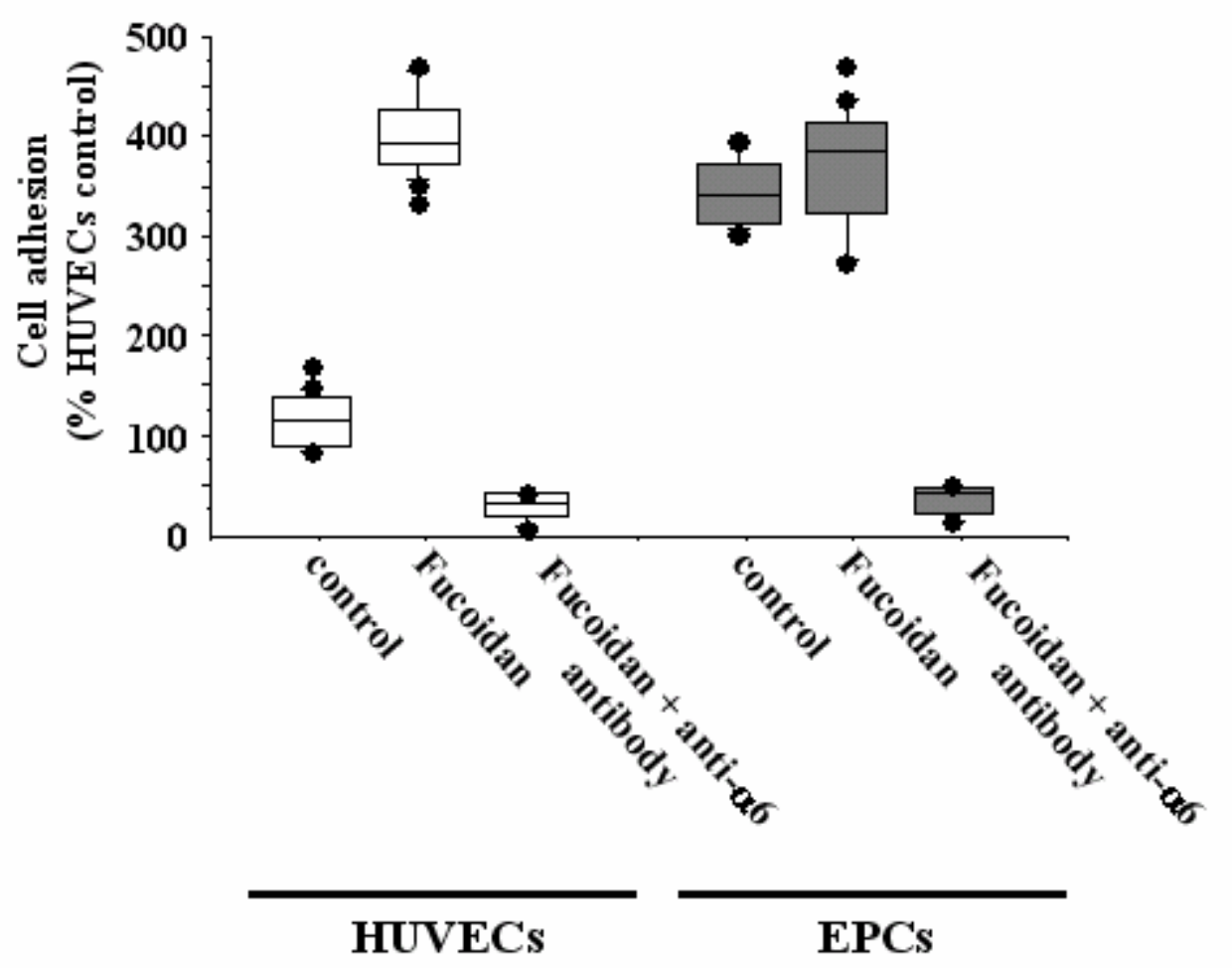

\subsection{Fucoidan-stimulated EPC migration is associated with cytoskeleton changes.}

As the integrin $\alpha 6 \beta 1$ can regulate the adhesion and, thus, the migration of EPC, we examined the effect of fucoidan on EPC motility and migration towards VEGF. As shown in Figure 6A, control EPC contained abundant radial stress fibres. Fucoidan treatment induced a reorganisation of the cytoskeleton, with emergence of cell protrusions characteristic of the motile and migratory phenotype (Fig. 6A), and fucoidan-treated EPC migrated faster than untreated EPC (control, Fig. 6B). Fucoidan-pretreated EPC were 2.5-fold more motile than control EPC $(p<0.01)$ (Fig. 6B). Similar results were obtained with untreated EPC when VEGF (40 ng/ml - positive control) was present in the bottom well of the chamber. Fucoidan- 
pretreated EPC showed filamentous actin reorganization, which generated a small frontal protrusion (Fig. 6A, arrowheads).

Finally, fucoidan enhanced EPC chemotaxis towards VEGF (p<0.05, Fig. 6B).

Figure 6: Fucoidan pretreatment enhances EPC migration.

Panel A: EPC were plated in a 4-well chamber and maintained for 36 hours in the presence or absence of $10 \mu \mathrm{g} / \mathrm{ml}$ fucoidan in basal medium. Cells were fixed and actin fibres were stained with FITC-phalloidin conjugate and observed by confocal microscopy. Scale bar, $30 \mu \mathrm{m}$. Panel B: Before the migration assay, EPC were incubated for $36 \mathrm{~h}$ with or without $10 \mu \mathrm{g} / \mathrm{ml}$ fucoidan. The migration assay was performed in a chemotaxis chamber with or without the designated chemoattractants (MCP-1 (negative control) or VEGF (positive control) in the lower chamber. Data are presented as percentages, $100 \%$ corresponding to untreated cells. The results are representative of 5 experiments yielding similar results. ${ }^{*} \mathrm{p}<0.05$; ${ }^{* *} \mathrm{p}<0.01$; ${ }^{* * *} \mathrm{p}<0.001$.

A
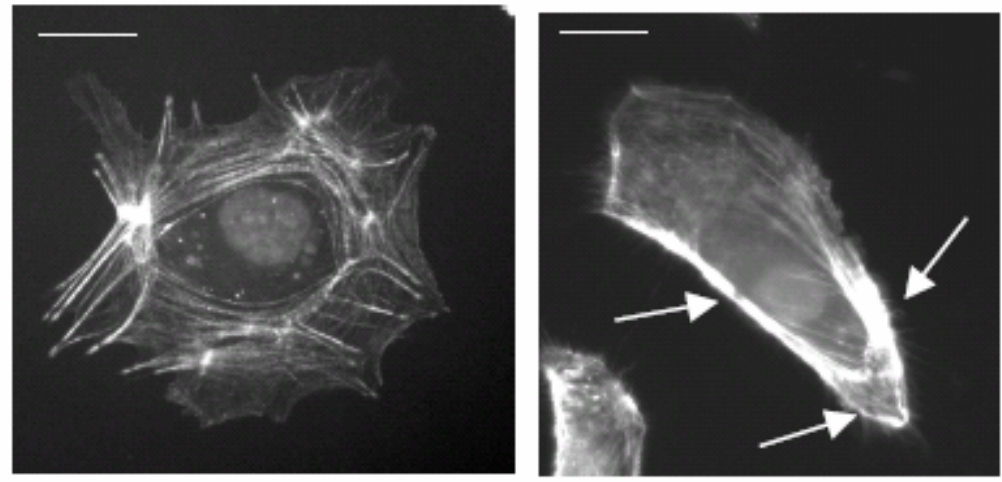

$\mathrm{B}$

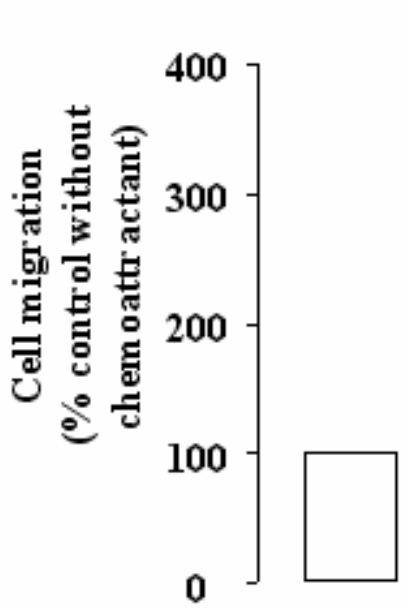

Chemoattractant $(\mathrm{ng} / \mathrm{ml}) \ldots$ lower chamber

- MCP-1 VEGF

$100 \quad 40$

Contr ol EPCs

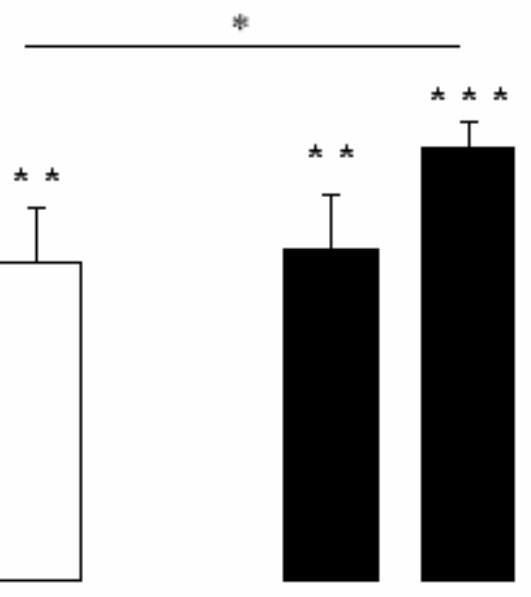

- VEGF

40

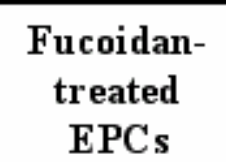




\section{DISCUSSION}

The aim of this study was to investigate the effect of a low-molecular-weight fucoidan fraction on the angiogenic activity of endothelial progenitor cells, which are promising candidates for cellular therapy of vascular diseases. These bone marrow-derived cells are able to participate directly in collateral vessel formation and display specific functional properties relative to mature vessel-wall endothelial cells [23].

We first confirmed that, in our experimental conditions, EPC extracted from human cord blood exhibited a stronger angiogenic capacity than mature endothelial cells (HUVEC), proliferating more strongly and producing significantly more tubular structures than HUVEC in the presence of FGF-2.

Having previously shown that fucoidan, a low-molecular-weight sulfated polysaccharide of marine origin, was able to enhance FGF-2-induced vascular tube formation by HUVEC in vitro $[17,18]$, here we investigated its effect on angiogenesis induced by EPC. In the presence of FGF-2, fucoidan induces a proangiogenic phenotype in human EPC. This phenotype includes both early angiogenic events (migration, and a mild effect on proliferation) and late events (differentiation into vascular cords). Indeed, fucoidan enhanced EPC proliferation and promoted EPC motility. Fucoidan pretreatment led to EPC-actin cytoskeleton changes, with the emergence of cell protrusions. Fucoidan-treated EPC showed enhanced migration in the Boyden chamber assay, including increased chemotaxis towards VEGF. Finally, fucoidan further enhanced the formation of FGF-2-induced vascular cord-like structures in Matrigel, whereas FGF-2 alone induced only a partial network.

Fucoidan did not affect $\alpha 6$-subunit expression by EPC cultured with FGF-2, whereas it led to $\alpha 6$ subunit overexpression by HUVEC in the same conditions, as previously described [20]. An anti- $\alpha 6$ antibody abrogated tube formation by both EPC and HUVEC. The fucoidanmediated increase in $\alpha 6$ integrin subunit expression was associated with increased HUVEC adhesion to laminin. Fucoidan pretreatment significantly increased HUVEC but not EPC adhesion to laminin, and this adhesion was significantly inhibited by a anti- $\alpha 6$ antibody. The $\alpha 6$ subunit is thus involved in these effects. Differences observed between EPC and HUVEC in adhesion assays are probably due to different total expression of $\alpha 6$. Baseline $\alpha 6$ subunit integrin expression was indeed stronger on EPC than on HUVEC. Therefore, a threshold level of $\alpha 6$ integrin subunit expression may be required for maximal adhesion and tubular morphogenesis in Matrigel. Theoretical analyses have shown that maximum migration speed requires intermediate adhesiveness [26]. The ability of fucoidan to enhance EPC motility without increasing their adhesiveness to laminin may be thus result in an optimal enhancement of cell locomotion.

In association with $\beta 1$ or $\beta 4, \alpha 6$ promotes cell adhesion and is thus required for endothelial cell adhesion to the underlying basement membrane, which promotes the integrity of mature vessels [27]. Our data suggest that EPC rather than HUVEC might preferentially attach to the basement membrane. This integrin profile could potentially allow circulating EPC to attach and differentiate at sites where laminin or other $\alpha 6$ adhesive matrices are exposed to flowing blood, after endothelial insults [28].

Our results suggest that fucoidan interacts directly with the cell membrane and also acts indirectly via FGF-2. Fucoidan may mediate FGF-2-induced EPC differentiation by interacting with a molecule that promotes endothelial cell adhesion, migration, proliferation and differentiation and that co-operates with a growth factor receptor, transducing the intracellular signals required to induce the angiogenic phenotype. We cannot rule out the possibility that free and cell-associated fucoidan may bind FGF-2 and confer a stable, receptor-compatible conformational change upon FGF-2, which might increase the affinity of the growth factors for their receptors. Experiments underway in our laboratory indicate that 
FITC-fucoidan binds to the cell membrane and is internalised within 30 minutes. The putative fucoidan receptor might contain a carbohydrate-binding domain that interacts with the carbohydrate backbone of fucoidan. Candidates include E-selectin and CD44, cell adhesion molecules that are present on the endothelial cell membrane and are expressed by EPC. Fucosylation of the receptor ESL-1 (E-selectin ligand-1) is necessary for E-selectin binding to its ligand. Therefore, fucoidan, a polyfucose, can provide the appropriate structural backbone to bind selectins. This is in keeping with previous studies showing the high affinity of selectins for a high-molecular-weight commercial fucoidan preparation [29-31]. However, a recent study showed that a commercial fucoidan was also able to bind to non selectin receptors such as integrin $\alpha_{M} \beta 2$ on myeloid cells [32]. Integrins can transduce extracellular signals analogous to signal transduction by growth factor receptors [33]. Future studies in our laboratory will address this question.

In summary, by endowing EPC with the capacity to migrate faster and to form an extensive tubular network, fucoidan pretreatment could be used for ex vivo expansion of EPC-based cell therapy products. This could enhance EPC-mediated vasculogenesis and homing, thereby improving treatment efficacy. 


\section{Reference List}

1. Carmeliet P, Angiogenesis in health and disease. Nat.Med. 2003; 9: 653-60.

2. Asahara T, Murohara T, Sullivan A, Silver M, van der Zee R, Li T, Witzenbichler G, Schatteman G, and Isner JM, Isolation of putative progenitor endothelial cells for angiogenesis. Science 1997; 275: 964-7.

3. Tateishi-Yuyama E, Matsubara H, Murohara T, Ikeda U, Shintani S, Masaki H, Amano K, Kishimoto Y, Yoshimoto K, Akashi H, Shimada K, Iwasaka T, and Imaizumi T, Therapeutic angiogenesis for patients with limb ischaemia by autologous transplantation of bone-marrow cells: a pilot study and a randomised controlled trial. Lancet 2002; 360: 427-35.

4. Assmus B, Schachinger V, Teupe C, Britten M, Lehmann R, Dobert N, Grunwald F, Aicher A, Urbich C, Martin H, Hoelzer D, Dimmeler S, and Zeiher AM, Transplantation of Progenitor Cells and Regeneration Enhancement in Acute Myocardial Infarction (TOPCARE-AMI). Circulation 2002; 106: 3009-17.

5. Britten MB, Abolmaali ND, Assmus B, Lehmann R, Honold J, Schmitt J, Vogl TJ, Martin H, Schachinger V, Dimmeler S, and Zeiher AM, Infarct remodeling after intracoronary progenitor cell treatment in patients with acute myocardial infarction (TOPCARE-AMI): mechanistic insights from serial contrast-enhanced magnetic resonance imaging. Circulation 2003; 108: 2212-8.

6. Murohara T, Ikeda H, Duan J, Shintani S, Sasaki K, Eguchi H, Onitsuka I, Matsui K, and Imaizumi T, Transplanted cord blood-derived endothelial precursor cells augment postnatal neovascularization. J.Clin.Invest. 2000; 105: 1527-36.

7. Murasawa S and Asahara T, Endothelial progenitor cells for vasculogenesis. Physiology. (Bethesda.) 2005; 20: 36-42.

8. Dawn B and Bolli R, Bone marrow cells for cardiac regeneration: the quest for the protagonist continues. Cardiovasc.Res. 2005; 65: 293-5.

9. Van Hennick PB, de Koning AE, and Ploemacher RE, Seeding efficiency of primitive human hematopoietic cells in Nonobese diabetic/severe combined immunodeficiency mice : implications for stem cell frequency assessment. Blood 1999; 94: 3055-61.

10. Reyes M, Dubek A, Jahagirdar B, Koodie L, Marker PH, and Verfaillie CM, Origin of endothelial progenitors in human postnatal bone marrow. J.Clin.Invest. 2002; 109: 33746.

11. Rafii S, Meeus S, Dias S, Hattori K, Heissig B, Shmelkov S, Rafii D, and Lyden D, Contribution of marrow-derived progenitors to vascular and cardiac regeneration. Semin.Cell Dev.Biol. 2002; 13: 61-7.

12. Ott I, Keller U, Knoedler M, Gotze KS, Doss K, Fischer P, Urlbauer K, Debus G, von BN, Rudelius M, Schomig A, Peschel C, and Oostendorp RA, Endothelial-like cells expanded from CD34+ blood cells improve left ventricular function after experimental myocardial infarction. FASEB J. 2005 in press. 
13. Vajkoczy P, Blum S, Lamparter M, Mailhammer R, Erber R, Engelhardt B, Vestweber D, and Hatzopoulos AK, Multistep nature of microvascular recruitment of ex vivoexpanded embryonic endothelial progenitor cells during tumor angiogenesis. J.Exp.Med. 2003; 197: 1755-65.

14. Colliec-Jouault S, Millet J, Helley D, Sinquin C, and Fischer AM, Effect of lowmolecular-weight fucoidan on experimental arterial thrombosis in the rabbit and rat. Thromb.Haemost. 2003; 1: 1114-5.

15. Koyanagi S, Tanigawa N, Nakagawa H, Soeda S, and Shimeno H, Oversulfation of fucoidan enhances its anti-angiogenic and antitumor activities. Biochem.Pharmacol. 2003; 65: 173-9.

16. Matsubara K, Xue C, Zhao X, Mori M, Sugawara T, and Hirata T, Effects of middle molecular weight fucoidans on in vitro and ex vivo angiogenesis of endothelial cells. Int.J.Mol.Med. 2005;15: 695-9.

17. Boisson-Vidal C, Haroun F, Ellouali M, Blondin C, Fischer AM, de Agostini A, and Jozefonvicz J, Review : Biological activities of polysaccharides from marine algae. Drugs Fut. 1995; 20: 1237-49.

18. Tissot B, Montdargent B, Chevolot L, Varenne A, Descroix S, Gareil P, and Daniel R, Interaction of fucoidan with the proteins of the complement classical pathway. Biochim.Biophys.Acta 2003; 1651: 5-16.

19. O'Leary R, Rerek M, and Wood EJ, Fucoidan modulates the effect of transforming growth factor (TGF)-beta1 on fibroblast proliferation and wound repopulation in in vitro models of dermal wound repair. Biol.Pharm.Bull. 2004; 27: 266-70.

20. Matou S, Helley D, Chabut D, Bros A, and Fischer AM, Effect of fucoidan on fibroblast growth factor-2-induced angiogenesis in vitro. Thromb.Res. 2002; 106: 213-21.

21. Chabut D, Fischer AM, Colliec-Jouault S, Laurendeau I, Matou S, Le Bonniec BF, and Helley D, Low molecular weight fucoidan and heparin enhance the basic fibroblast growth factor-induced tube formation of endothelial cells through heparan sulfatedependant $\alpha 6$ overexpression. Molecular Pharmacology 2003; 64: 696-702.

22. Nardella A, Chaubet F, Boisson-Vidal C, Blondin C, Durand P, and Jozefonvicz J, Anticoagulant low molecular weight fucans produced by radical process and ion exchange chromatography of high molecular weight fucans extracted from the brown seaweed Ascophyllum nodosum. Carbohydr.Res. 1996; 289: 201-8.

23. Bompais H, Chagraoui J, Canron X, Crisan M, Liu XH, Anjo A, Tolla-Le PC, Leboeuf M, Charbord P, Bikfalvi A, and Uzan G, Human endothelial cells derived from circulating progenitors display specific functional properties compared with mature vessel wall endothelial cells. Blood 2004; 103: 2577-84.

24. Trochon V, Mabilat-Pragnon C, Bertrand P, Legrand Y, Soria J, Soria C, Delpech B, and He L, Hyaluronectin blocks the stimulatory effect of hyaluronan-derived fragments on endothelial cells during angiogenesis in vitro. FEBS Lett. 1997; 418: 6-10. 
25. Haroun F, Lindenmeyer F, Lu H, Soria C, Jozefonvicz J, and Boisson-Vidal C, In vitro effect of fucans on MDA-MB231 tumor cell adhesion and invasion. Anticancer Res. 2002; 22: 214-21.

26. DiMilla PA, Barbee K, and Lauffenburger DA, Mathematical model for the effects of adhesion and mechanics on cell migration speed. Biophys.J. 1991; 60: 15-37.

27. Hiran TS, Mazurkiewicz JE, Kreienberg P, Rice FL, and LaFlamme SE, Endothelial expression of the alpha6beta4 integrin is negatively regulated during angiogenesis. J.Cell Sci. 2003; 116: 3771-81.

28. Grant DS and Kleinman HK, Regulation of capillary formation by laminin and other components of the extracellular matrix. EXS 1997; 79: 317-33.

29. Church FC, Meade JB, Treanor RE, and Whinna HC, Antithrombin activity of fucoidan. The interaction of fucoidan with heparin cofactor II, antithrombin III, and thrombin. J.Biol.Chem. 1989; 264: 3618-23.

30. Preobrazhenskaya ME, Berman AE, Mikhailov VI, Ushakova NA, Mazurov AV, Semenov AV, Usov AI, Nifant'ev NE, and Bovin NV, Fucoidan inhibits leukocyte recruitment in a model peritoneal inflammation in rat and blocks interaction of Pselectin with its carbohydrate ligand. Biochem.Mol.Biol.Int. 1997; 43: 443-51.

31. Handa K, Nudelman ED, Stroud MR, Shiozawa T, and Hakomori S, Selectin GMP-140 (CD62; PADGEM) binds to sialosyl-Le(a) and sialosyl-Le(x), and sulfated glycans modulate this binding. Biochem.Biophys.Res.Commun. 1991; 181: 1223-30.

32. Hidalgo A, Peired AJ, Weiss LA, Katayama Y, and Frenette PS, The integrin alphaMbeta2 anchors hematopoietic progenitors in the bone marrow during enforced mobilization. Blood 2004; 104: 993-1001.

33. Smyth SS and Patterson C, Tiny dancers: the integrin-growth factor nexus in angiogenic signaling. J.Cell Biol. 2002; 158: 17-21.

\section{ACKNOWLEDGMENTS}

This work was supported by grants from IFREMER (GDR "Les polysaccharides microbiens d'origine marine et leurs potentiels biologiques”) and Réseau “cellules souches INSERM”. Faouzia Zemani was supported by a fellowship from "Groupe Etude de l'Hémostase et de la Thrombose" and Daniele Benisvy by a fellowship from "Fondation pour la Recherche Medicale". The authors thank Prof M. Aiach for fruitful discussions and C. Sinquin for preparing the fucoidan fractions. Hôpital des Diaconnesses in Paris and Hôpital des Instructions et des Armées de Begin in Saint Mandé provided umbilical cord blood samples. 